\title{
COVID-19 Case Detection: Cuba's Active Screening Approach
}

\section{Conner Gorry MA}

Meningitis, neuropathy, HIV, dengue-since the 1960s, Cuba has faced its share of epidemics. More recently, Cuban health professionals tackled domestic outbreaks of H1N1 (2009) and Zika (2016), and worked alongside colleagues from around the world to stem Ebola in West Africa; all three were categorized by WHO as public health emergencies of international concern.

In December 2019, China reported its first cluster of pneumonia cases, later identified as the novel coronavirus disease COVID-19. In January 2020, Cuban authorities convened a multi-sector working group coordinated by the Ministry of Public Health (MINSAP) and Civil Defense to tailor its national epidemic control plan to confront the rapidly-spreading disease. The plan features a national reporting system and database, with standard protocols including early case detection, contact tracing and regularly-scheduled public health messaging. In late January, no fewer than six ministries, plus the National Sports and Recreation Institute, Customs, Immigration and national media outlets, came together to adapt domestic protocols and design multi-phase control and response mechanisms to combat the SARS-CoV-2 virus.

Cuba's previous experience with epidemics, tackled in the context of a universal health system, was an advantage. A national diagnostic and surveillance network was already in place, supported by provincial Hygiene, Epidemiology and Microbiology Centers, a national network of WHO-compliant diagnostic laboratories, and the national reference center lab for infectious diseases in Havana's Pedro Kourí Tropical Medicine Institute (IPK).

Trained human resources also proved advantageous in mounting a rapid COVID-19 response. From infectious disease specialists, microbiologists and trained lab technicians, to epidemiologists and more than 13,000 family doctors[1] and nurses who serve people in neighborhoods and hillsides across the island, health authorities had the necessary personnel in place to detect, isolate and monitor cases-key elements in epidemic control and prevention.

Following a nine-day, international fact-finding mission in February, a joint WHO-China report found that among the most important elements allowing China to control its outbreak were "high quality non-pharmaceutical public health measures" including extremely proactive surveillance, rapid case detection and isolation, rigorous contact tracing and community involvement.[2] Infectious disease and public health experts agreed: interrupting the transmission chain of COVID-19 through prevention, surveillance and rapid case detection are proven, pro-active strategies for mitigating this threat. To do this, Cuba turned to another deep store of human resources on the island: medical students.

\section{Preparing for National Active Screening}

Before Cuba confirmed its first case of COVID-19 on March 11, deans of medical schools across the country[3] issued a call for student volunteers to participate in early case detection through active screening. Over 28,000 responded-not only Cubans,

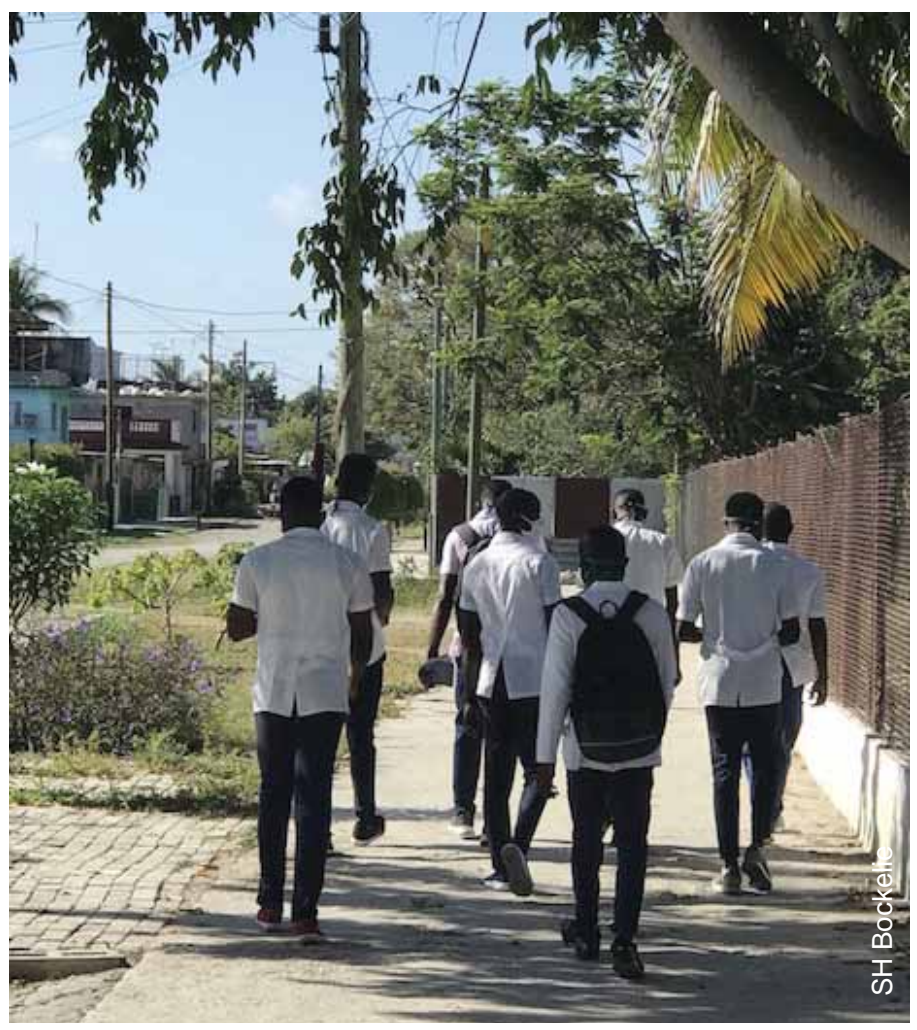

Medical student volunteers are the backbone of Cuba's active screening campaign.

but also students from the USA, Canada, Chad, South Africa, El Salvador, Colombia and elsewhere, studying for their degrees at the Latin American School of Medicine (ELAM) and at other Cuban medical schools. Since the Cuban curriculum incorporates community as well as classroom learning, and public health is melded with clinical medicine, the prospective volunteers were accustomed to working with local populations. And other infectious disease outbreaks had also given them active screening experience. "I've been doing one to two weeks active screening since my first year," says Olive Albanese, a fifth-year US ELAM student. As part of our training, "we go door-to-door screening for dengue, Zika and other vector-borne illnesses."

Nevertheless, to arm each participant with knowledge specific to the SARS-CoV-2 virus that causes COVID-19, a two-stage orientation was held before students first headed into the field on March 17. The initial stage detailed characteristics of the virus, including the most common symptoms and modes of transmission, supplemented by experiences from other countries and current scientific findings. The second stage updated students on new evidence regarding COVID-19, detailed how the active screening would be organized, in which health area they would work and instructions on carrying out that work in the community. "These students are a tremendous resource," says Dr Eduardo Alemañy, dean of the Medical University of Havana's Salvador Allende Faculty of Medicine. "Incorporating them into active 


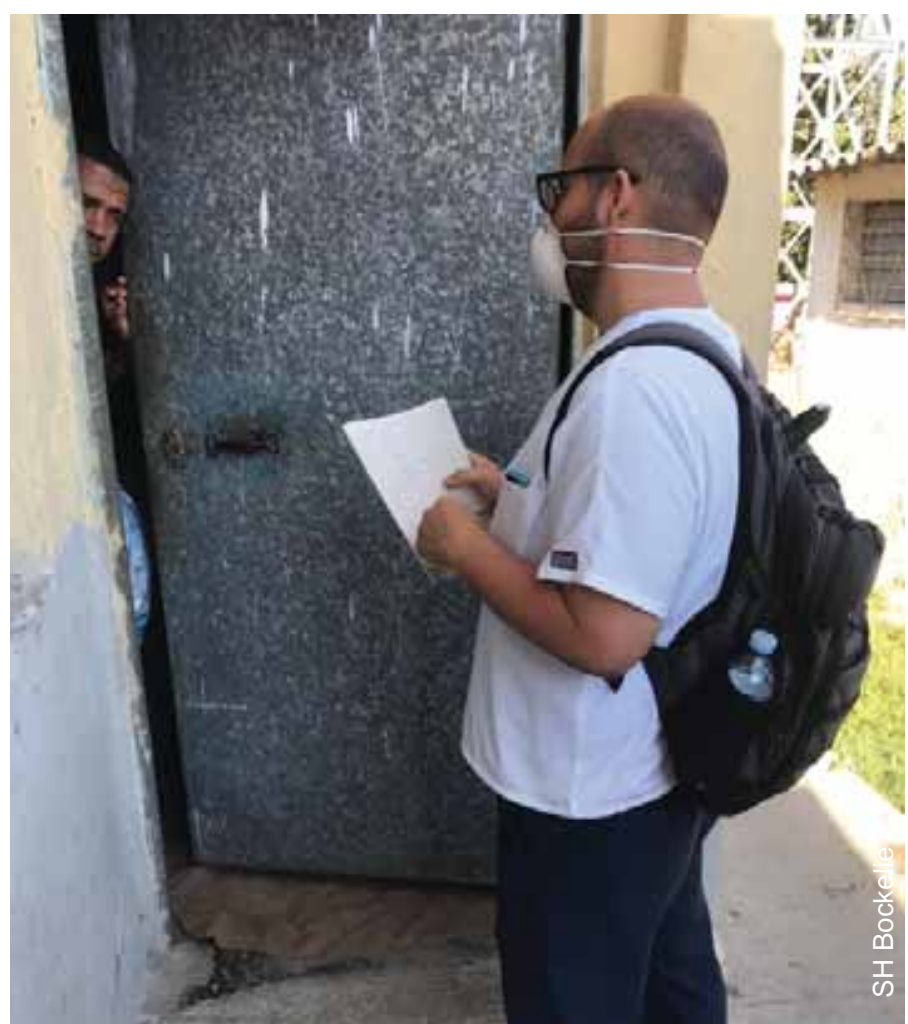

Fifth-year US ELAM student Alexander Ruiz began active screening in mid-March.

screening makes a concrete contribution to their professional development, but also means we haven't had to train community workers. The students have previous screening knowledge, training and field experience. This has helped us gain ground and save time in early case detection."

The pragmatism of a medical school curriculum that combines classroom work with community-based practice becomes applicable and actionable during infectious disease outbreaks. Sol Henrik Bockelie, a fifth-year ELAM student from Bremerton, Washington, USA, was completing the public health segment of the curriculum before COVID-19 reached Cuban shores. Classwork included infectious disease control and the importance of "preventive measures and the need for a strong, centrally-organized public health response using a multi-sector approach." From the classroom, Bockelie joined his colleagues in the field: "each student was responsible for conducting a transversal study on the health situation in 30 homes." Known as Continuous Assessment and Risk Evaluation (CARE; dispensarización in Spanish, Eds.), this is usually conducted annually (by family doctors) and evaluates all aspects of health-disease prevalence and incidence, prevention, treatment, diet, addiction-in each household across Cuba. "We discuss family planning and inter-family relations, assess building infrastructure and test local water supplies." In the new situation, he says, this hands-on experience is paying off: "we just submitted our CARE results and the project definitely helped us when it came time to begin community screening for COVID-19."

Given the transmission dynamics of the virus, volunteers received special instruction provided by epidemiologists, medi-

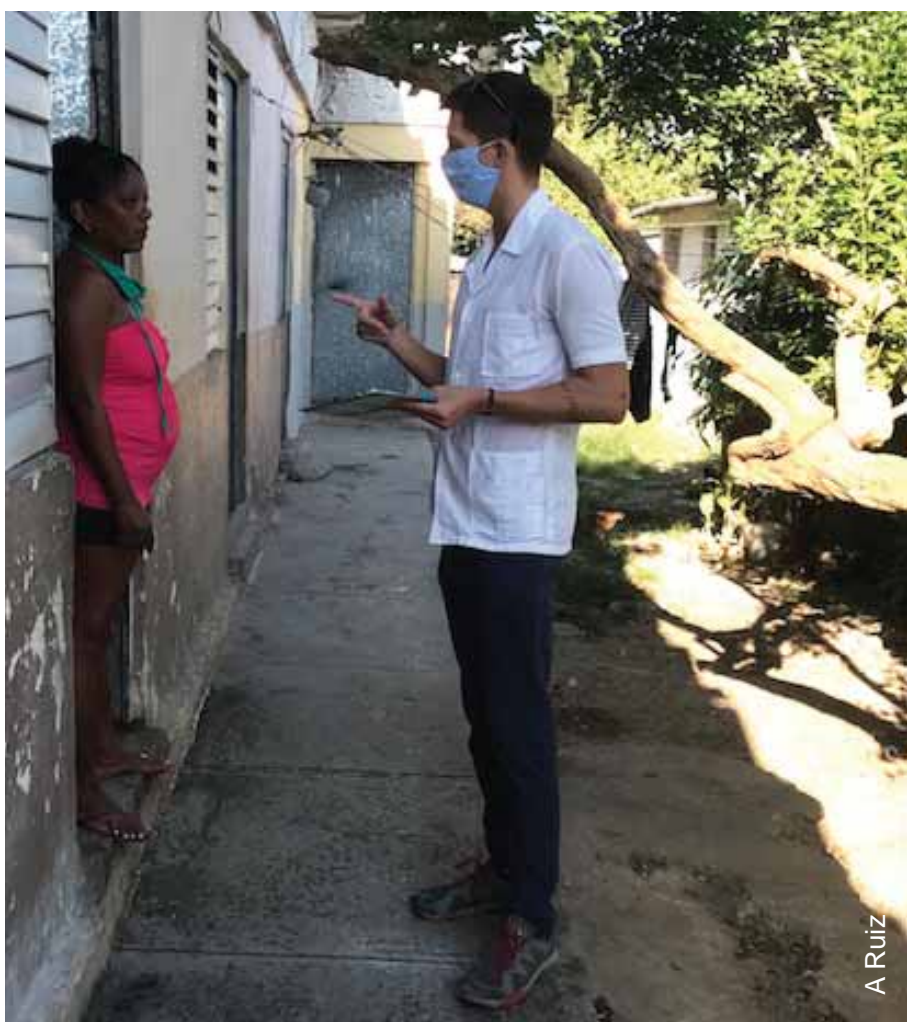

Fifth-year US ELAM student Sol Henrik Bockelie screening doorto-door in the Altahabana neighborhood of the Cuban capital.

cal professors and municipal health directors on how to protect themselves and the health of others while in the community. This included the proper use of masks, gloves, antibacterial gel and bleach solutions; discussions on how to properly conduct doorto-door screening in ways that reflect the bioethics of respect for interviewees; what questions to ask; what to report and how; and the all-important element of physical distancing. This last has required adaptations to the usual approach. Cuba's is an extremely sociable culture, where community-based public health campaigns are a fact of life and health workers-whether doctors, nurses, students, inspectors or epidemiologists-are often neighbors, received affectionately and even invited into people's homes. But the importance of social distancing during COVID-19 changed that: student screeners maintain at least one and a half to two yards between them and residents at all times; they don't enter homes, touch doors or pass through entry gates.

The original active screening strategy called for student volunteers from the third, fourth and fifth years (Cuba's is a six-year curriculum). But in the first week of April, when Cuba entered the disease's second epidemiological phase of limited local transmission, the call was expanded. Now all medical students willing to volunteer, regardless of their year of study, participate in active screening. As of this writing, over 9 million of the island's total 11.4 million population, have been visited in their homes and places of work. Says Gabriela Reguera, a fourth-year Cuban student from the Victoria de Girón Institute (Medical University of Havana), volunteering in Havana's Vedado neighborhood: "many people in my health area are elderly and more vulnerable; we owe it to them to help keep them healthy. It's my commitment and calling and the least I can do for my community." 


\section{Organization, Work Flow \& Information Retrieved}

Cuba's integrated primary health care system, with family doctor-and-nurse teams in every neighborhood, each one reporting to a community polyclinic, allowed for a quick rollout of the active screening strategy. First, a work flow between the family doctors offices, polyclinics and medical school deans was designed, whereby the latter were responsible for recruiting and placing volunteers in their medical school's municipality.[4] Polyclinics, most already accredited as teaching sites, then designated a coordinating professor to organize the teams, who were assigned to family doctors' offices.

Working in pairs, students are responsible for daily visits to their assigned homes and workplaces; up to ten pairs may be supervised by a single family doctor and nurse, depending on the size of the office's catchment area. Every morning, screeners report to their family doctor's office and head out on foot to visit each home, business or entity-for instance, day care centers still open for essential workers with small children-within their universe.

"Together my screening partner and I will visit between 80 and 100 homes a day," says Alexander Ruiz, a fifth-year, Cubanborn ELAM student from Jacksonville, Florida, USA, who joined the active screening in mid-March. "We visit residences, as well as private and government-run businesses, making sure to revisit those places which were closed during previous screening attempts. My work has taken me to different areas: affluent, suburban neighborhoods, apartment complexes, and shelters and transitional housing for people whose homes were destroyed in hurricanes." Given both rising temperatures as Cuba

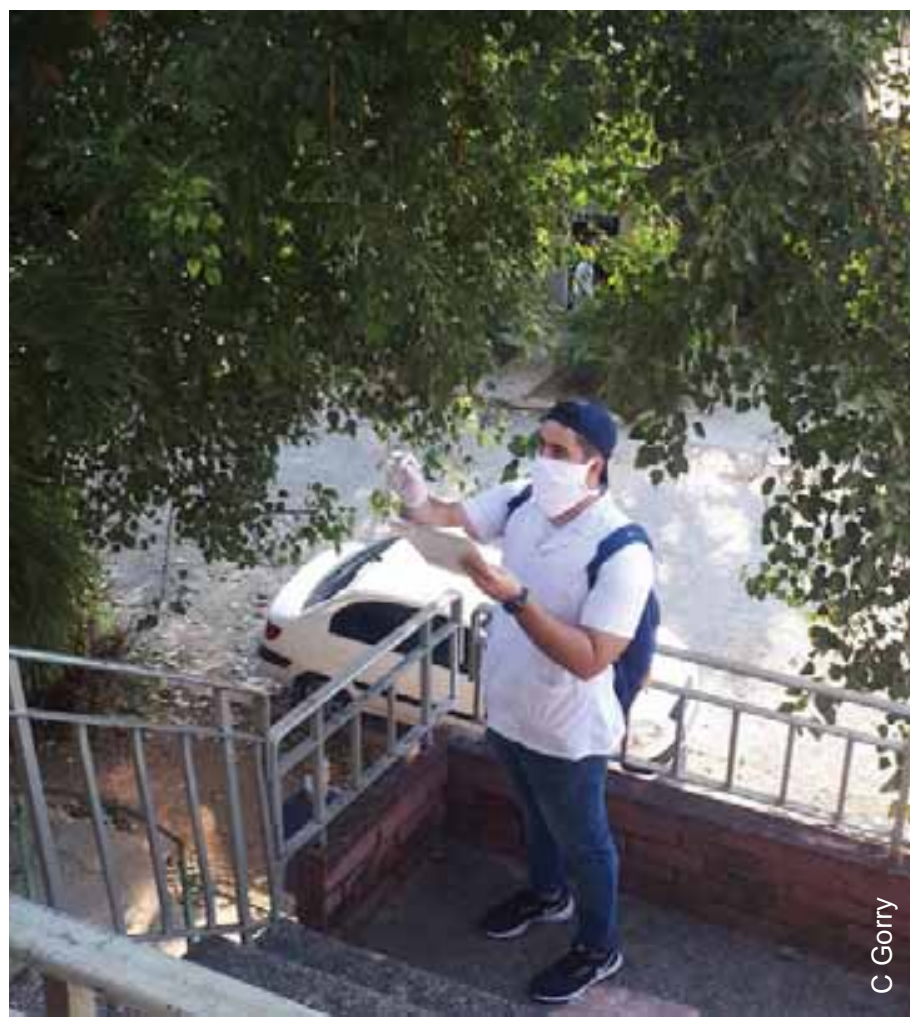

A Cuban medical student performs active screening in health area served by family doctor-nurse office \#9, Playa municipality, Havana. approaches summer, and also the need to continue students' studies, screening is carried out in mornings only, from 8:00 AM to noon.

Information screened for includes the number and ages of those living in the home or working in the business; if anyone has traveled outside Cuba or had contact with someone who has recently traveled abroad; if so, when and to which countries; and if anyone has a fever, respiratory difficulties or other symptoms. All results are reported back to the family doctor at the end of each screening shift. The information is then transferred to the coordinating professor at the polyclinic, consolidated and passed on to polyclinic administrators for database entry and statistical reporting.

The family doctor provides follow up with those individuals who describe symptoms, as well as with those who have had contact with a foreigner or someone who has traveled abroad. Vulnerable groups-including people with disabilities, those over 60 , individuals who live alone and pregnant women-also receive follow-up by the family doctor. Anyone who has had contact with a confirmed case is remitted to one of 36 isolation centers dotting the country for an obligatory 14-day quarantine, screened for 26 other viral respiratory diseases, and tested for COVID-19.

\section{Screening at the Secondary Care Level}

As the epidemiological situation evolves, so do the health measures to limit the spread of COVID-19. New actions, along with the number of confirmed cases, patients' health status, geographic location, number of tests conducted, as

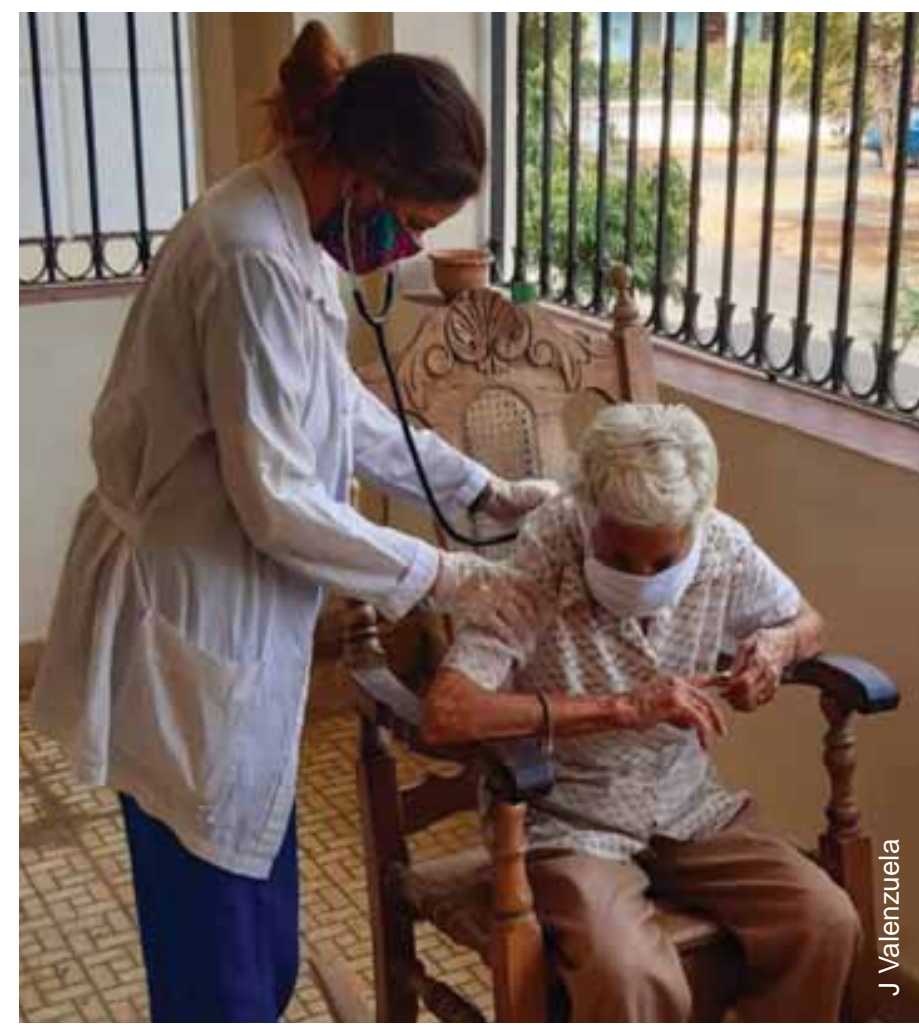

Cuban student Gabriela Reguera checks her grandmother (with whom she lives) for respiratory symptoms. 


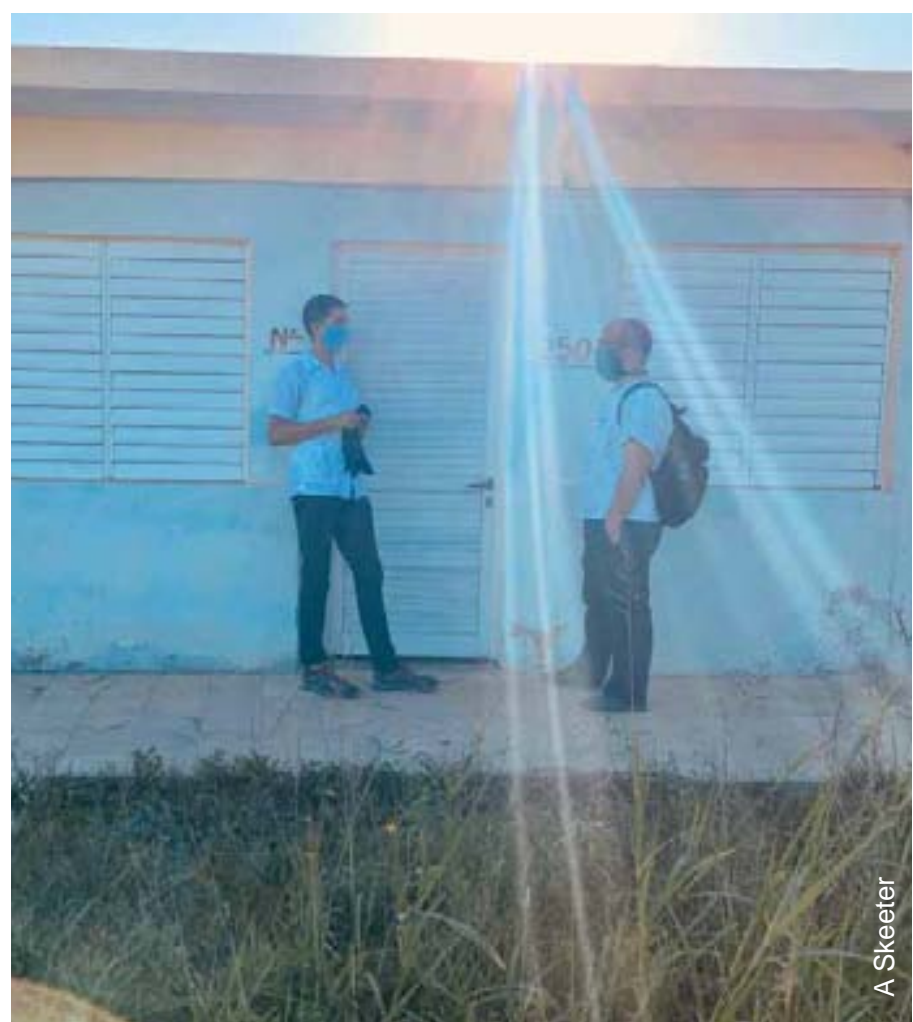

US ELAM students Sol Henrik Bockelie and Alexander Ruiz meet each morning at family doctor-nurse office \#250, Boyeros municipality to begin their screening day.

well as recovered and death totals, are made public in daily press conferences held by President Miguel Díaz-Canel, Health Minister Dr José Ángel Portal and National Director of Epidemiology Dr Francisco Durán. As the virus continued to spread into April, for example, separate intake wards were established in general and specialized hospitals for patients presenting with respiratory problems.

Dr Yatson Jesús Sánchez, chief of Emergency Services at the Pepe Portillo Pediatric Hospital in Pinar del Río Province, put out the call for screening volunteers declaring, "I need 16 crazy Quixotes, possessing the soul and calling of a doctor, to accompany me in the fight for our dearest treasure, our children."[5] A few hours later, he had his Quixotes-14 Cuban and two foreign pediatric residents-who signed up to help staff the pediatric respiratory screening center in Cuba's westernmost province. The provisional COVID-19 center includes an emergency room, separate wards for confirmed cases, possible cases and patients under observation, as well as an intensive care unit.

Working 24-hour shifts, followed by three days' rest, residents receive children with respiratory problems in the emergency room and immediately perform comprehensive clinical exams and screen for a variety of respiratory infections. Those suspected as possible carriers of the SARS-CoV-2 virus are separated into the appropriate wards for observation, treatment and follow-up, while the rest are remitted to a specialized consult for acute respiratory infections. Babies 18 months or younger who have had contact with someone who has trav- eled internationally are immediately remitted for observation after a comprehensive epidemiological survey and detailed conversation with the parents involving contact-tracing; residents are accompanied by a specialist throughout their shift, never seeing patients alone.

The screening center enforces international protocols for safeguarding the health of both patients and staff. This means that before each consult, residents don sterilized surgical caps, masks, goggles and gloves; changing these after each patient; and taking care to properly remove and dispose of these in separate, sterile receptacles for each item. Standard surgical hand-washing techniques are used and exams are performed at a distance of three feet, with the patient's back to the resident or specialist. After each screening, all equipment and the exam room are disinfected. Says resident Dr David Gómez: "It's vitally important that every surface is disinfected and to maintain proper distance so we're separated from patients who might accidentally sneeze or cough near us-which can happen when you're examining for respiratory infections. I've become an obsessive-compulsive hand washer!"[5]

\section{Context-Specific Challenges}

While Cuba's national epidemic prevention and control plan, together with applied infectious disease experience and robust human resources are proving advantageous during this global crisis, certain difficulties in the country's health system predate-and are compounded by-the onset of COVID-19. One is resource scarcity, exacerbated by the decades-long US embargo, which continues to block medical and other aid

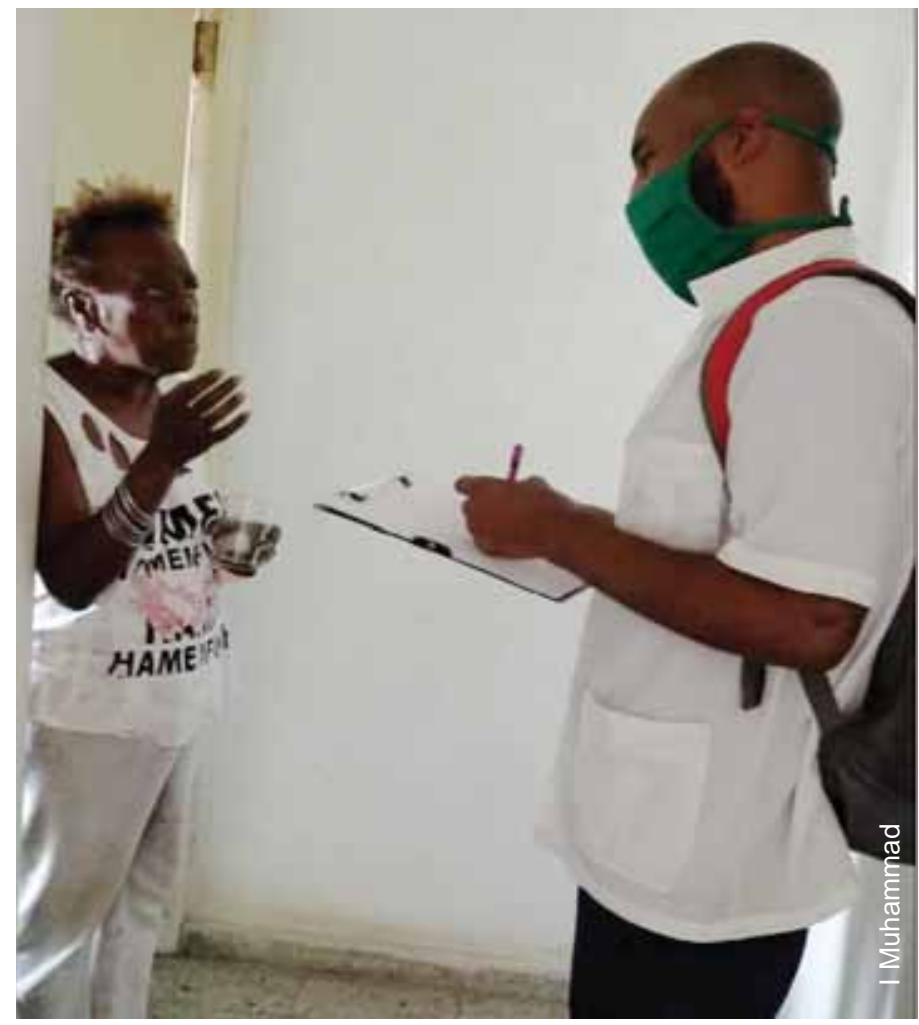

US ELAM student Ivan Smiley conducting active screening in Boyeros Municipality, Havana. 
to Cuba from third countries.[6] Thus, domestic production of face masks, bleach and personal protective equipment has been accelerated, with some factories completely retooling their production lines. Nevertheless, other imported supplies integral to population health including food, raw materials for biotech products, replacement parts for medical equipment, gasoline for ambulances and other items necessary for stemming the pandemic, are directly affected by the US policy and by Cuba's limited economy.

Another challenge is low risk perception. As with HIV and other communicable diseases, confidence in the universal health system to protect and treat the population against COVID-19 is a double-edged sword, looming large during active screening. "Cuba had very few cases when we began our work in the community and our active screening wasn't taken as seriously by some local residents," says fourth-year ELAM student Ivan Smiley from Houston, Texas, USA, who began active screening on March 19. Nevertheless, in the later weeks, says Smiley, he has noticed that "the community has been more than cooperative, is grateful for what we're doing and that has only intensified." He attributes the change to the daily press conferences by the President, Health Minister and National Director of Epidemiology, news specials devoted to all aspects of prevention, control and treatment of COVID-19, as well as the efforts of private businesses, local law enforcement and other sectors.

"There is also a psychological element to the screenings," says Sol Henrik Bockelie. "When people see us with face masks and checking on each household, they're reminded of the seriousness of the situation." This provides an educational opportunity, he says: "We remind them to maintain physical distancing of 6 feet, to leave home only if essential, wash their hands with soap for more than 20 seconds, wear a face mask in public, and to clean or remove footwear before re-entering their house. People are always very kind."

Whole-population screening, however, has revealed another challenge, now a regular topic in the public briefings: hiding symptoms. Speaking specifically to the effectiveness of active screening during his April 7 briefing, Health Minister Portal said: "The population mustn't hide symptoms. You must alert screeners and family doctors to any symptoms. One of the latest fatalities was a patient who had not reported respiratory symptoms; nor did their family report those symptoms."[7] He went on to say that early detection is key and that lamentably, some patients are arriving at emergency rooms too late. To address this, screeners have adjusted their questioning both in length and depth.

Finally, Cuba's population demographics and general health picture have required an emphasis on vulnerable groups, including those with chronic diseases such as diabetes, hypertension and asthma, and those over the age of 60-since both pre-existing chronic conditions and advanced age have been identified as COVID-19 risk factors. Due to the fact that some $20 \%$ of Cubans are already older than 60 , with the associated increase in co-morbidities, screeners are emphasizing early detection among the country's senior citizens, prioritizing them for longer, in-depth interviews and follow-up by their family doctors. Initial screening for everyone "over

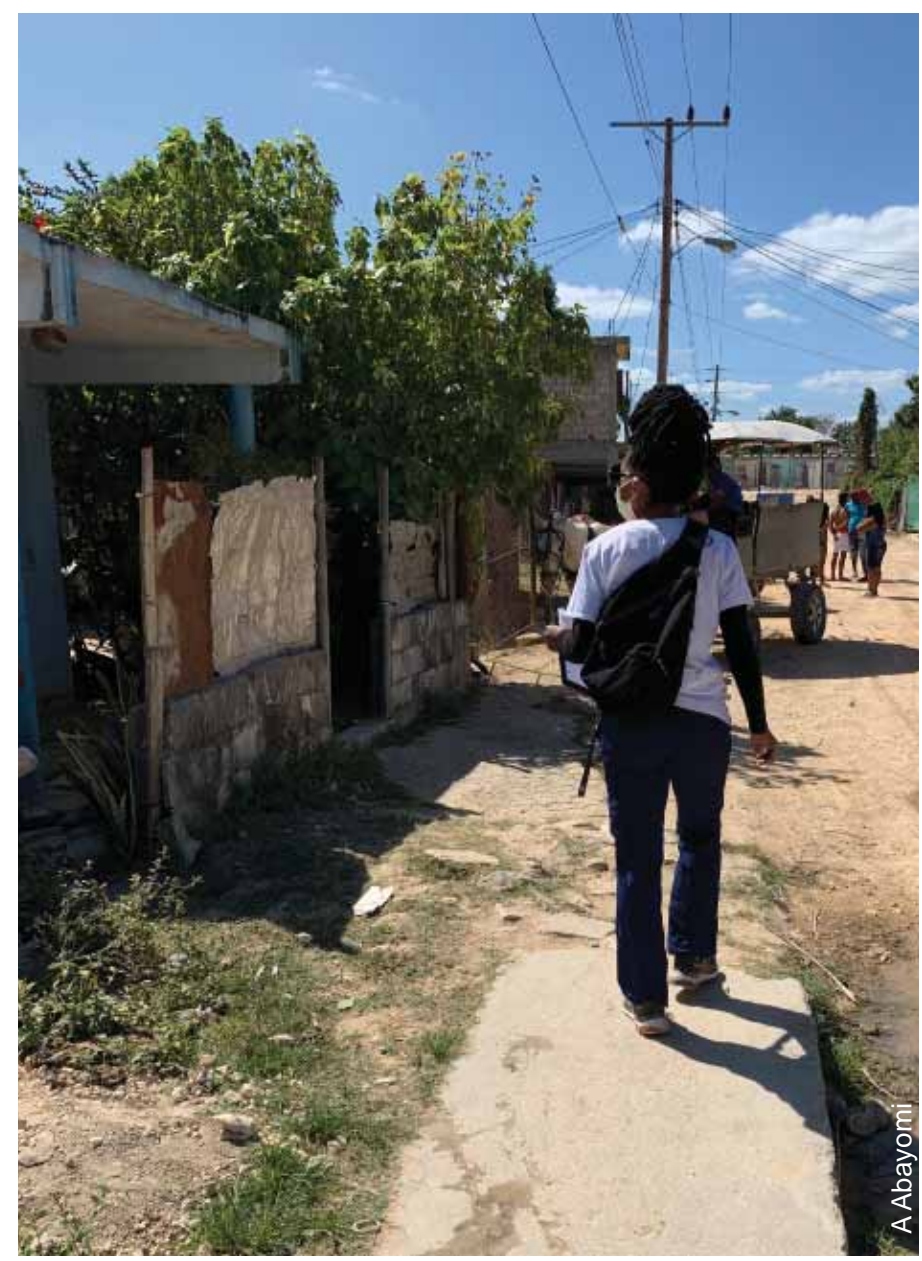

Six days a week, third-year US ELAM student Kaylaa Banks is actively screening at homes and businesses.

60 was probably the most daunting task," says Smiley. "In a 12-story apartment building, you can find a lot of people who are over 60."

Despite the public's general cooperation, daily screening in record-breaking heat during a global pandemic can be stressful. But Ruiz, the fifth-year ELAM student from Jacksonville, says he channels the stress into energy: "Some people are afraid for themselves and their families and even burst into tears over what may happen in the future. Although screening can be taxing, being able to validate their concerns and give them hope provides me all the energy I need." Smiley says "Cuba is one of the calmest places to be on this planet right now...l've been handling the stress by studying for the USMLES (US medical licensing exams), listening to music and communicating with friends and family back home." Yet, he admits he is often drained at the end of his screening shift, citing the relentless sun and general global uncertainty around COVID-19. Kaylaa Banks, a third-year ELAM student from Riverside County, California, USA, has implemented a well-body and mind routine to keep her stress at bay. "I move my body at least 15 minutes every day-doing yoga, a short workout or even simple stretches." Meditation and eating lots of fresh fruits and vegetables are also part of her daily regimen. And she keeps a journal. "I find joy in writing, knowing 
that one day l'll be able to look back on COVID-19 as something we all conquered together."

\section{Conclusions}

As the world continues to struggle against the pandemic caused by SARS-CoV-2 evidence from a variety of contexts shows that certain factors are fundamental in the fight against this common enemy, including: the political will to prioritize public health, community participation and cooperation in prevention measures, and the early case detection that leads to timely treatment. With an accessible universal system rooted in community-based, primary health care and deep reserves of trained and experienced health professionals, Cuba was better prepared than many developing countries when COVID-19 struck-despite material scarcity, sometimes acute. From the beginning of the outbreak, time-saving efforts to seek out every suspected case were made possible by the willingness of thousands of trained medical students, with previous experience, to conduct total-population active screening. Honing their skills in the field, based on humanistic principles and ethical commitment to population and individual health, bodes well for their futures and that of their patients. $-1 /$ -

\section{Notes \& References}

1. National Health Statistics and Medical Records Division (CU). Anuario Estadístico de Salud 2018. Havana: Ministry of Public Health (CU); 2019 [cited 2020 Apr 10]. 206 p. http://files.sld.cu/bvscuba/files/2019/04/Anuario-Electróni co-Español-2018-ed-2019-compressed.pdf. Spanish.

2. World Health Organization [Internet]. Report of the WHO-China Joint Mission on Coronavirus Disease (COVID-19), 28 Feb 2020. [cited 2020 Apr 7]. Geneva: World Health Organization. Available at: https://www.who.int/pu blications-detail/report-of-the-who-china-joint-mission-on-coronavirus -disease-2019-(covid-19)

3. Cuba has 13 medical universities (with 25 faculties) plus the Latin American School of Medicine, which has graduated some 30,000 MDs from over 100 countries since opening its doors in 1999, primarily low-income students who receive six-year scholarships from the Cuban government.

4. In the case of those medical schools responsible for more than one municipality (Havana has three such schools within the Medical University of Ha-

vana), work flow is distributed between the dean and several local municipal leaders.

5. Hernández MA. Valientes: Profe, ¿qué es lo que hay hacer? [Internet]. Havana: Cubadebate; 2020 Apr 4 [cited 2020 Apr 10]. Available at: http://www .cubadebate.cu/especiales/2020/04/04/valientes-profe-que-es-lo-que-hay -hacer/\#.XpDNKa2ZO9Z. Spanish.

6. Weissenstein M. Cuba: US embargo blocks coronavirus aid shipment from Asia [Internet]. New York: APNews; 2020 Apr 3 [cited 2020 Apr 11]. Available at: https://apnews.com/2858fbaa2dd5460fa2988b888fc53748

7. Fariñas Acosta L. Ministerio de Salud: Cuba se prepara para más casos de COVID-19, no bajar ni un milímetro la percepción de riesgo [Internet]. Havana: Cubadebate; 2020 Apr 8 [cited 2020 Apr 11]. Available at: http://www.cubadebate .cu/noticias/2020/04/08/ministro-de-salud-cuba-se-prepara-para-mas-casos -de-covid-19-no-bajar-un-milimetro-la-percepcion-de-riesgo/\#anexo-1348559. Spanish. 